\title{
Stability-indicating capillary zone electrophoresis assay for the analysis of linezolid in tablets
}

\author{
Cristiani Lopes Capistrano Gonçalves de Oliveira ${ }^{1^{*}}$, Hérida Regina Nunes Salgado², \\ Maria de Lourdes Leite Moraes ${ }^{3}$
}

\begin{abstract}
${ }^{1}$ Department of Pharmacy, College of Pharmacy Dentistry and Nursing, Federal University of Ceará, Fortaleza, CE, Brazil, ${ }^{2}$ Department of Drugs and Medicines, Faculty of Pharmaceutical Sciences, State University of São Paulo, Araraquara, SP, Brazil, ${ }^{3}$ Department of Chemistry, Institute of Environmental, Chemical and Pharmaceutical Sciences, Federal University of São Paulo, Diadema, SP, Brazil
\end{abstract}

\begin{abstract}
A simple and fast alternative methodology using capillary zone electrophoresis (CZE) to analyze linezolid and its cationic photodegradation products in tablets has been developed. The separation was carried out on fused silica capillary and conducted using $100 \mathrm{mM}$ formic acid $(\mathrm{pH} \mathrm{3.0)}$ ) and by applying 30 $\mathrm{KV}$ voltage. Detection was performed at UV $254 \mathrm{~nm}$. The optimized method was validated in terms of linearity, limits of detection and quantification, precision (repeatability), stability studies (selectivity) and accuracy. Good linearity $\left(8-20 \mathrm{mg} \mathrm{L}^{-1}\right)$ was obtained and the limit of detection was $0.95 \mathrm{mg} \mathrm{L}^{-1}$. The greatest advantages of the CZE method were the rapid set-up of instrumentation and capillary equilibration, short analysis time (12 min), low running cost and low waste generation. The method showed good stability in determining linezolid submitted to degradation by light and to a climatic chamber and can be used as an alternative for evaluation in stability studies of linezolid in tablets, as well as for the analysis of the drug in raw materials and finished products.
\end{abstract}

Keywords: Capillary-electrophoresis/assay. Linezolid/tablets/stability. Pharmaceutical-drugs.

\section{INTRODUCTION}

Linezolid, $N$-(( $(S)$-3-(3-Fluoro-4-morpholinophenyl)-2-oxo-5-oxazolidinyl)methyl)acetamide (Figure 1), is a member of a new class of antibiotics, the oxazolidinones (Marchese, Schito, 2001), and it was the first oxazolidinone to be developed and approved for clinical use (Di Paolo et al., 2010). Linezolid (LNZ) is currently the only antimicrobial agent which can be administered orally, being rapidly absorbed following oral administration and eliminated via renal and non-renal routes (Boak et al., 2014). It is particularly important in cases where intravenous access is difficult and the patients require outpatient therapy (Itani et al., 2005; Kalil, Puumala, Stoner, 2006). LNZ has a wide spectrum of activity against gram-positive organisms and appears to be an effective option of treatment when compared to

\footnotetext{
*Correspondence: C. Oliveira. Departamento de Farmácia, Universidade Federal do Ceará. Rua Capitão Francisco Pedro, n. 1210, Rodolfo Teófilo - CEP: 60430-370 - Fortaleza-Ceará. E-mail: cristianilopes@ufc.br
}

vancomycin(Patel, Gallagher, 2015; Silva, Monteiro Neto, Sejas, 2007).

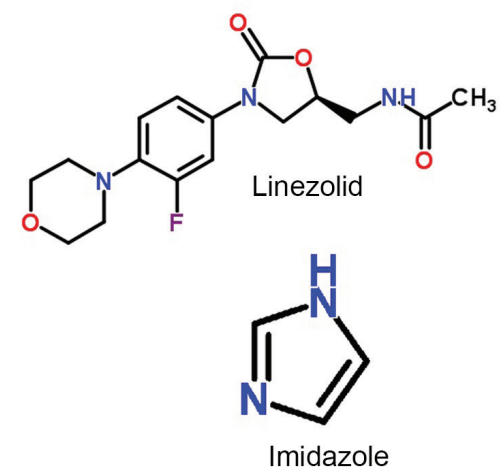

FIGURE 1 - Chemical structure of Linezolid (LNZ) and Imidazole (IS) used in the study.

Analysis of LNZ and its degradation products are usually assayed by high-performance liquid chromatography (HPLC) and spectrometry (Erlich et al., 2001; Krishna-Reddy et al., 2002; Patel et al., 
2007; Merli et al., 2011; La Marca et al., 2012; Cios, Kus, Szymura-Oleksiak, 2013; Chavda et al., 2016); however, this technique has important limitations such as the high cost of the analysis and the excessive generation of residues due to the use of organic solvents. Capillary electrophoresis (CE) has also been described as an alternative to HPLC for LNZ assays. The range of pharmaceutical applications of CE is similar to HPLC and its advantages include appreciably short analysis times, low residue generation, use of aqueous solvents, high resolution and specificity (Landers, 1997). CE presents several modes of operation, with zone capillary electrophoresis (CZE) and micellar electrokinetic capillary chromatography (MEKC) being the most commonly used.

MEKC has been used to determine LNZ in human serum samples (Kitahashi, Furuta, 2002). The authors used $25 \mathrm{mM}$ borate buffer ( $\mathrm{pH} 10.0$ ) containing $80 \mathrm{mM}$ sodium dodecyl sulphate (SDS) as running buffer. They compared CZE and MEKC and concluded that MEKC enabled a separation (with a migration time of $14 \mathrm{~min}$ ) without overlapping with the peaks of impurities in serum and improvement in the theoretical plate number. An improvement of the method was published by the same authors in 2004 (Kitahashi, Furuta, 2004) lowering the $\mathrm{pH}$ of borate buffer $(\mathrm{pH} \mathrm{8.0)}$ ) and the concentration of SDS $(50 \mathrm{mM})$. There was the addition of $7 \mathrm{M}$ urea as an additive to increase the LNZ dissolution into the running buffer. The advantages included direct serum injection without pretreatment and lower migration time (5.5 $\mathrm{min})$. CE was also used for the separation of enantiomers from LNZ (Michalska, Pajchel, Tyski, 2008a; Bednarek, Bocian, Michalska, 2008). Michaska, Pajchel, and Tyski (2008a) used MEKC to performed the LNZ enantiomeric separation. Charged $\beta$-cyclodextrins $(\beta-C D)$ was added to the running buffer to carry out the separation with a migration time of $15 \mathrm{~min}$.

Due to its chemical structure, LNZ is highly unstable under alkaline conditions and several degradation studies have been done to evaluate the compounds obtained under conditions of alkaline stress. Alkaline degradation and photodegradation products have been investigated by chromatography and spectrophotometry in LNZ commercial (tablets) and injectable samples (Bebawy, 2003; Lopes, Salgado, 2009; Lopes, Salgado, 2010; Kawy, Weshahy, Shokry, 2012; Hegazy et al., 2014). Chiral impurities from LNZ have been analyzed by MEKC in linezolid solution for infusion (Michalska, Pajchel, Tyski, 2008b).

CZE has never been used in LNZ tablet assay until now. The few scientific papers addressing $C E$ for linezolid applied MEKC to LNZ samples in the injectable form. The aim of this work was to develop a stabilityindicating CZE/UV assay method to analyze linezolid in the cationic form (under $\mathrm{pH} 4.0$ ), which can be applied to studies of stability and determination of content of linezolid in the presence of degradation products. This is the first paper that uses CZE to analyze linezolid in its pharmaceutical form of tablets.

\section{MATERIAL AND METHOD}

\section{Chemicals}

All chemicals were of analytical grade and used as received. LNZ reference substance was obtained from "Synfine research" Chemical Company (Canada) and HPLC analysis showed that it contained $99.3 \%$ of LNZ. Linezolid tablets $\left(\right.$ Zyvox $\left.^{\circledR}\right)$ were commercially obtained and were claimed to contain $600 \mathrm{mg}$ of active drug (Pfizer, Brazil). Imidazole (purity 99.0\%) from Merck was used as internal standard. Formic acid $85 \%$ was purchased from Synth. Ultrapure water was deionized by using a Milli-Q gradient system A10 (Millipore, Bedford, MA, USA) and was used to prepare all buffers.

\section{Equipment}

CE analyses were performed on a model PA800 Plus, Beckman Coulter, equipped with a UV/Vis detector. Bare fused silica capillaries with $75 \mu \mathrm{m}$ i.d. were purchased from Polymicro Technologies, Phoenix, AZ, U.S.A. The capillary detection length was $50 \mathrm{~cm}$ and the total length $60 \mathrm{~cm}$. The samples were injected by pressure $(10 \mathrm{~s}$ at 0.5 psi) and the detection was performed at $256 \mathrm{~nm}$. Stock solutions of formic acid (1 M) were prepared in water and stored under refrigeration. Working background electrolyte consisted of $100 \mathrm{mM}$ formic acid ( $\mathrm{pH}$ 3.0) and the applied voltage was $30 \mathrm{kV}$.

\section{Pre-treatment of capillary}

The capillary was conditioned with $1 \mathrm{M} \mathrm{NaOH}$ for $30 \mathrm{~min}$, followed by the passage of ultra pure water (Milli-Q) for $10 \mathrm{~min}$ and a running buffer for $20 \mathrm{~min}$. At the beginning of each working day, the capillary was conditioned with a flush of $\mathrm{NaOH}$ (5 min), ultrapure water (5 min) and electrolyte (10 min). Between each running, the capillary was washed with $1 \mathrm{M} \mathrm{NaOH}$ followed by ultrapure water for $2 \mathrm{~min}$ and with background electrolyte for $5 \mathrm{~min}$. 


\section{Preparation of the solutions}

\section{Preparation of standard solution and internal standard}

Stock solutions of LNZ (reference substance) and imidazole (internal standard) were prepared in deionized water. Linezolid stock solution was prepared by accurately weighing $10 \mathrm{mg}$ of linezolid in a $100 \mathrm{~mL}$ volumetric flask, and then dissolving this quantity in deionized water. The solution was sonicated for $10 \mathrm{~min}$ and brought to volume with water. For the calibration curve, working standard solutions were prepared by dilution of the linezolid stock solution to obtain six different concentrations within the range of interest, in this case, $8-20 \mathrm{mg} \mathrm{mL}^{-1}$. All the solutions were prepared in triplicate.

\section{Preparation of sample solution}

An amount of powder equivalent to $500 \mathrm{mg} \mathrm{LNZ}$ was transferred to a $1000 \mathrm{~mL}$ volumetric flask with deionized water and shaken for $20 \mathrm{~min}$, followed by the dilution to volume with deionized water $\left(500 \mathrm{mg} \mathrm{L}^{-1}\right)$. A $10 \mathrm{~mL}$ aliquot of this solution was transferred to a 100 $\mathrm{mL}$ volumetric flask $\left(50 \mathrm{mg} \mathrm{L}^{-1}\right)$. Lastly, an aliquot of this solution was dissolved in the deionized water to obtain a solution with a final concentration of $12 \mathrm{mg} \mathrm{L}^{-1}$. This solution was used in the stability studies and in the assay of commercial tablets of linezolid.

\section{Method validation}

The method validation assays were carried out according to the International Conference on Harmonization Guidelines (ICH, 2005). The analyzed parameters were: linearity, limits of detection and quantification, precision (repeatability), selectivity, accuracy.

\section{Linearity}

For the assay of linearity stock solutions of LNZ reference substance were prepared at six concentration levels from $8.0-20 \mathrm{mg} \mathrm{L}^{-1}$ and injected in triplicate. The linearity was evaluated by the least square regression method.

\section{Limits of detection and quantification}

The limits of detection (LOD) and quantification (LOQ) were calculated according to the equations: $\mathrm{LOD}=3 \mathrm{~S}_{\mathrm{y} / \mathrm{x}} / \mathrm{b}$ and LOQ $=10 \mathrm{~S}_{\mathrm{y} / \mathrm{x}} / \mathrm{b}$

\section{Precision}

The precision of the method was evaluated by the repeatability (intra-assay). Repeatability of the method was studied by analyzing samples of tablets, at the same concentration, within 1 day and under the same experimental conditions.

\section{Stability studies (Selectivity)}

Selectivity and forced degradation studies were conducted according to the ICH Guidelines by introducing a sample of linezolid sample solution to different forced degradation conditions using thermal and photolytic analysis. For the selectivity test of the proposed method, tablet powder of LNZ was prepared and exposed to light (254 nm) and climate chamber $\left(40{ }^{\circ} \mathrm{C} / 75 \%\right.$ for 90 days) to determine the effects of irradiation and humidity/ temperature on the stability of LNZ in its solid state and was subsequently analyzed.

\section{Accuracy}

The accuracy of the method was evaluated by comparing the results obtained in the simultaneous determination of linezolid tablets by HPLC and capillary electrophoresis. Upon test "t-paired" it was found that the average values obtained by the two techniques did not differ significantly at a confidence level of $95 \%$.

\section{RESULTS AND DISCUSSION}

\section{Optimization CE/UV separation}

In capillary electrophoresis, the choice of buffer or background electrolyte has direct implications for the optimization of separation since the $\mathrm{pH}$ of the electrolyte determines the effective mobility by decisively affecting the degree of dissociation (Landers, 1997). For basic compounds, it is recommended that the $\mathrm{pH}$ of the background electrolyte is around 2.5. This would provide better selectivity since acidic or neutral interferents exhibit negative mobility or simply do not have mobility, respectively, thus not being detected. Although LNZ does not have basic character, it has a nitrogen atom, which can be ionized and migrated as cation in CZE. Michalska, Pajchel and Tyski (2008a) studied the influence of $\mathrm{pH}$ on the behavior of LNZ in CE and found that it is protonated under $\mathrm{pH} 4.0$ (LNZ has $\mathrm{pKa}$ around 1.8).

In this study formic acid under $\mathrm{pH} 3.0$ was used as background electrolyte. Formic acid showed a good baseline at the work concentration $(100 \mathrm{mM})$. Figure 2 shows the electropherogram of LNZ standard and the blank sample. Imidazole was used as internal standard and methanol as a marker of electroosmotic flow (EOF). It can be observed that the LNZ peak migrates before the EOF, which ensures that it is still protonated at this $\mathrm{pH}$; however, 
as the EOF is smaller and the electrophoretic mobility is also low, it takes 12 minutes to migrate.

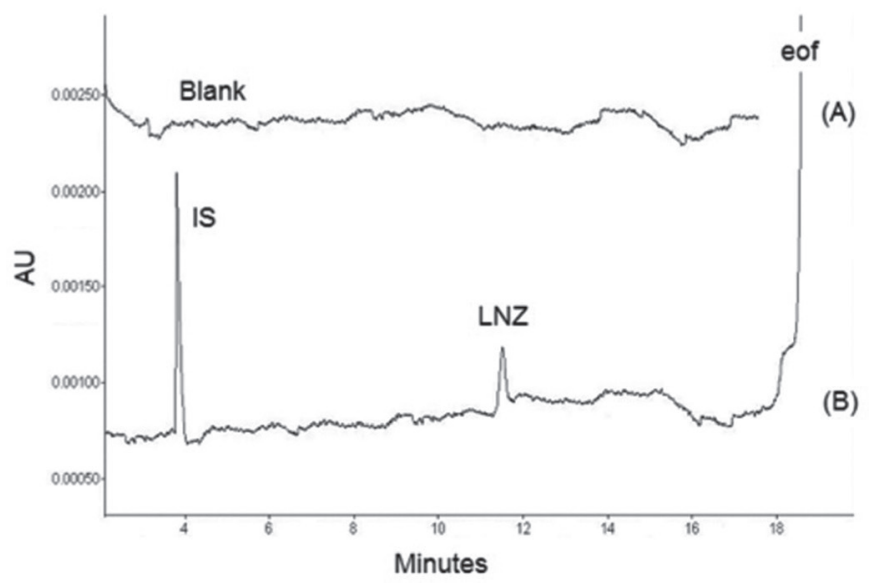

FIGURE 2 - CZE of (A) - Blank sample, (B) - linezolid (chemical reference). CE/UV conditions: $100 \mathrm{mM}$ formic acid, $\mathrm{pH} 3.0$, applied voltage $+30 \mathrm{kV}$, injection by pressure $(0.5 \mathrm{psi}$ for $10 \mathrm{~s}$ ) and detection at $254 \mathrm{~nm}$. Caption: methanol as eof marker and imidazole as IS (internal standard).

\section{Method validation}

The method was validated in respect to parameters including linearity, limits of detection (LOD) and quantitation (LOQ), precision, stability studies (selectivity) and accuracy.

\section{Linearity, limits of detection and quantitation}

Linearity studies were performed by linear regression standard curve. Lower values of parameters like standard error (S.E.) of slope and intercept (Table I) indicated high precision of the proposed methods. Also, the mean slope and intercept values are within the $95 \%$ confidence interval. Goodness of fit of the regression equations was supported by high regression coefficient values and lower calculated $F$-values (Table I). With data from the evaluation of linearity, we calculated the limits of detection (LOD), quantification (LOQ) and the determination coefficient $\left(\mathrm{r}^{2}\right)$, which are presented in Table I. This analysis was done at $95 \%$ confidence and 5 $\%$ significance level.

\section{Precision}

The data obtained from precision experiments are given in Table II for intra-day precision studies. Each concentration was injected six times $(n=6)$. The $\%$ RSD values for intra-day precision study was $<4.0 \%$ confirming that the method was sufficiently precise (Table II).
TABLE I - Statistical analysis of calibration graphs and analytical data in the determination of linezolid by electrophoresis method $(n=6)$

\begin{tabular}{lc}
\hline Parameters & $\begin{array}{c}\text { Proposed electrophoresis } \\
\text { method }\end{array}$ \\
\hline Regression analysis & $275.30(6.27)$ \\
$\quad$ Slope $\left(\right.$ S.E. $\left.{ }^{\mathrm{a}}\right)$ & $-226.46(87.22)$ \\
$\quad$ Intercept $\left(\mathrm{S} . \mathrm{E} .^{\mathrm{a}}\right)$ & 0.9943 \\
$\quad$ Correlation coefficient $\left(r^{2}\right)$ & $\mathrm{y}=275.30 \mathrm{x}-226.46$ \\
Equation & 1926.1430 \\
Analysis of variance & \\
$\quad$ Linear regression & \\
Validation parameters & $8-20$ \\
$\quad$ Linearity $\left(\mathrm{mg} \mathrm{L}^{-1}\right)$ & 0.95 \\
$\quad$ LOD $\left(\mathrm{mg} \mathrm{L}^{-1}\right)$ & 3.16 \\
$\quad$ LOQ $\left(\mathrm{mg} \mathrm{L}^{-1}\right)$ &
\end{tabular}

${ }^{\mathrm{a}}$ Standard error of mean. ${ }^{\mathrm{b}}$ Corresponding critical values for $F$ at $\mathrm{p}<0.05$

TABLE II - Comparison of CE and HPLC methods for determination of linezolid in Tablets $(600 \mathrm{mg})$

\begin{tabular}{lcc}
\hline & $\begin{array}{c}\text { CE assay } \\
\text { (content, \%) }\end{array}$ & $\begin{array}{c}\text { HPLC method } \\
\text { (content, \%) }\end{array}$ \\
\hline Results & 100.91 & 103.5 \\
& 98.64 & 100.32 \\
& 99.14 & 100.81 \\
& 106.84 & 105.00 \\
& 105.71 & 101.31 \\
& 107.56 & 101.31 \\
Mean & 103.13 & 102.04 \\
Number of samples & 6 & 6 \\
R.S.D. (\%) & 3.90 & 1.77 \\
$\mathrm{t}_{\text {calculated }}$ & 0.73 & \\
\hline
\end{tabular}

*Student's $t$-value for $p=0.05, n=6, t_{\text {tabulated }}=2.447$

\section{Stability studies (Selectivity)}

Figure 3 presents the electropherograms of LNZ tablet submitted to degradation by light. The sample of LNZ was injected in high concentration to visualize the degradation products. The appearance of two major peaks ( 1 and 2) can be observed, corresponding to cationic degradation products in just 10 days of exposure to light (LNZ solid state). These degradation products probably contain nitrogen in their structure, which is protonated at this $\mathrm{pH}$ and migrate as cationic form during electrophoresis. It is noted that the elution of 
these degradation products are very close, assuming that the chemical structures are very similar. During 90 days of exposure in the UVC light the degradation products primarily formed, increasing over the course of time, indicating that these products can be characterized as primary products of degradation of linezolid submitted to light exposure. Figure 4 shows the electropherogram of linezolid tablet subjected to degradation in a climatic

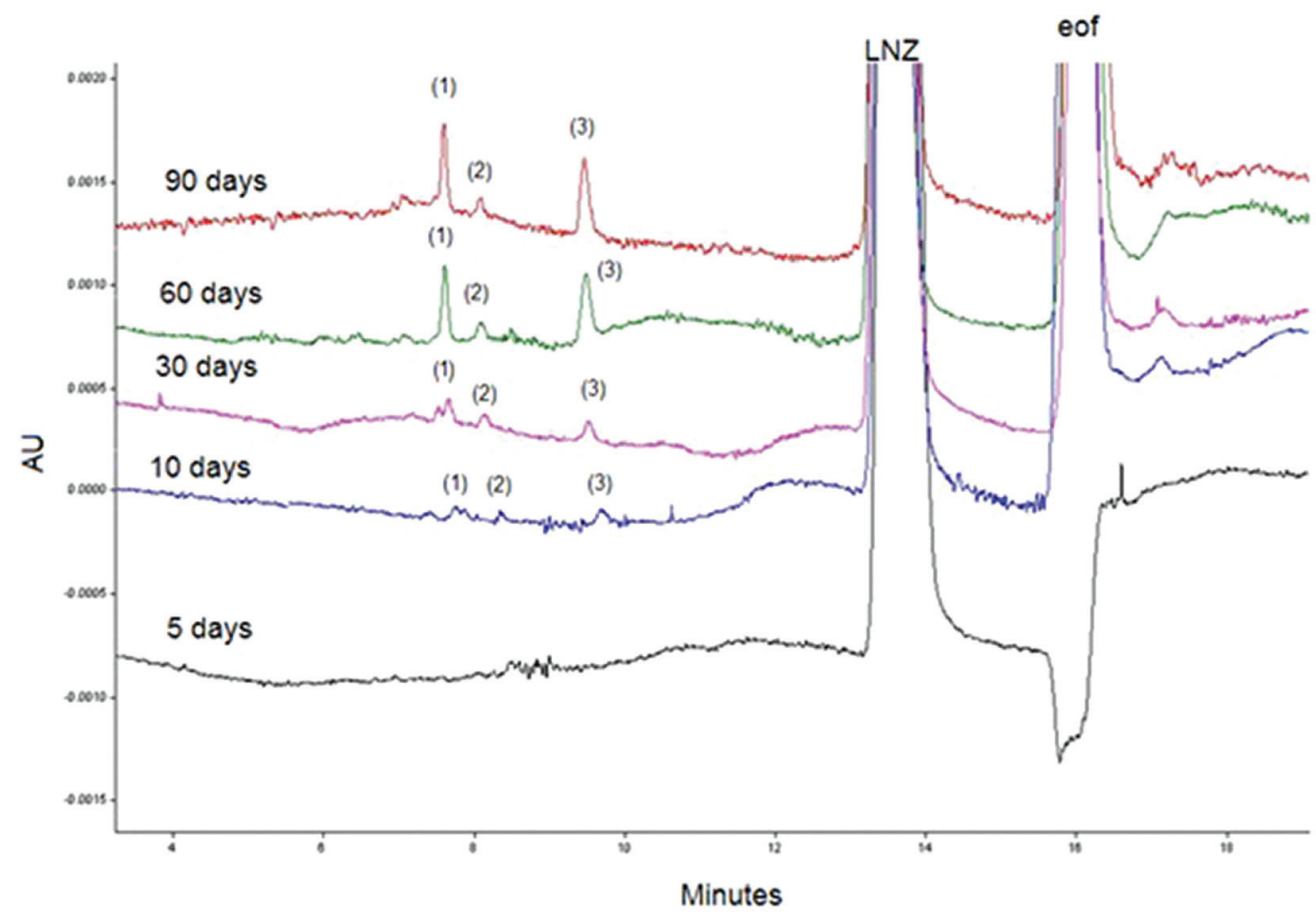

FIGURE 3 - Electropherogram of photodegradation products of LNZ tablet submitted to light UVC (254 nm).

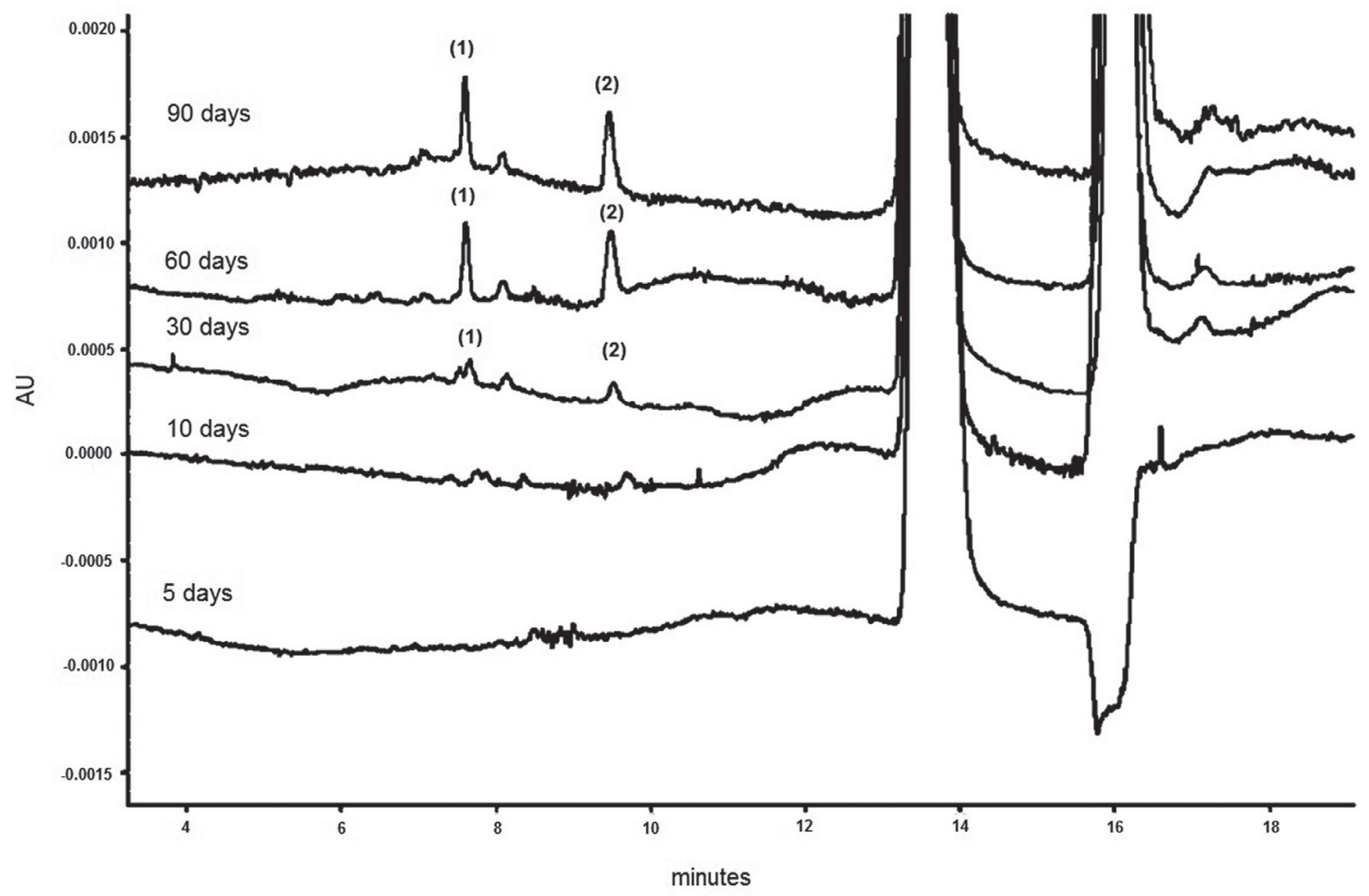

FIGURE 4 - Electropherogram of degradation products of LNZ tablet submitted to climate chamber $\left(40{ }^{\circ} \mathrm{C} / 75 \%\right)$. 
chamber $\left(40^{\circ} \mathrm{C} / 75 \%\right)$. The degradation in the solid state is slow and time consuming, but it is consistent with the adverse conditions of temperature and humidity in different countries during transport and distribution of this drug. In this analysis, we can watch the beginning of the formation of degradation products after 30 days. This electropherogram is consistent with the data obtained earlier by HPLC (Lopes, Salgado, 2009).

\section{Accuracy}

With the statistics of the two methods analyzed, it was found that there is no statistical difference between the methods, confirming the accuracy of the method by capillary electrophoresis (Table II).

\section{Analysis of pharmaceutical tablets}

The validated method was applied for the assay of commercial tablets containing $600 \mathrm{mg}$ of linezolid. Results of the determination were found to be $103.13 \pm 3.90 \%$ (RSD). The method was statistically compared with the HPLC method (Table II). The averages of the validated methods were compared by t-test and statistical differences were not observed between them.

\section{CONCLUSION}

In this work the linezolid tablets and its cationic degradation products were determined by CZE in low $\mathrm{pH}$. This simple and validated methodology provided good linearity, precision and detection limits. CZE method was shown to be specific because there was no interference of the excipients present in the formulation of the linezolid tablets, as well as showing the ability to distinctly determine the LNZ from its degradation products. It could be used as an alternative to HPLC in the determination of the content and stability in studies of the LNZ tablets.

\section{ACKNOWLEDGEMENTS}

This work was supported by PACD-FCFAr-UNESP (Araraquara, Brazil), FAPESP (São Paulo, Brazil), FUNDUNEP (São Paulo, Brazil) and CNPq (Brasília, Brazil). C.L.C.G. de Oliveira was funded by FAPESP (process number 06/53874-4) and H.R.N.S. was funded by CNPq (process number 304824/2013/5). Thanks to Esalab (Beckman Brazil) and Laboratory of Chromatography and Capillary Electrophoresis - USP for the use of the CE equipment.

\section{CONFLICT OF INTEREST STATEMENT}

The authors declare that there are no conflicts of interest regarding this manuscript.

\section{REFERENCES}

Bebawy LI. Stability-indicating methods for the determination of linezolid in the presence of its alkaline-induced degradation products. Talanta 2003;60(5):945-53, 2003.

Bednarek E, Bociana W, Michalskab K. NMR and molecular modeling study, as complementary techniques to capillary electrophoresis method to elucidate the separation mechanism of linezolid enantiomers. J Chromatogr A. 2008;119(1-2):164-71.

Boak LM, Rayner CR, Grayson ML, Paterson DL, Spelman $\mathrm{D}$, khumra S. et al. Clinical population pharmacokinetics and toxicodynamics of linezolid. Antimicrob Agents Chemother. 2014;58(4): 2334-43.

Chavda RN, Yadav HN, Hinge MA, Shing RD, Patel ES, Patel DR. Development and validation of analytical method for simultaneous estimation of cefuroxime axetil and linezolid in tablet dosage form. Int J Pharma Sci Res. 2016;7(4):172-80.

Cios A, Kus K, Szymura-Oleksiak J. Determination of linezolid in human serum by reversed-phase high-performance liquid chromatography with ultraviolet and diode array detection. Acta Poloniae Pharm Drug Res. 2013;70(4):631-41.

Di Paolo A, Malacarne P, Guidotti E, Danesi R, Del Tacca M. Pharmacological issues of linezolid: an updated critical review. Clin Pharmacokinet. 2010;49(7):439-47.

Ehrlich M, Trittler R, Daschner FD, Kuemmerer K. A new and rapid method for monitoring the new oxazolidinone antibiotic linezolid in serum and urine by high performance liquid chromatography-integrated sample preparation. J Chromatogr B. 2001;755(1-2):373-77.

Hegazy MAEL-M, Eissa MS, El-Sattar OIA, El-kawy MA. Two and three way spectrophotometric-assisted multivariate determination of linezolid in the presence of its alkalineband oxidative degradation products and application to pharmaceutical formulation. Spectrochim Acta Part A: Mol Biomol Spectrosc. 2014;128:231-42. 
International Conference on Harmonization. ICH. Validation of analytical procedures: text and methodology Q2 R1. Geneva: International Conference on Harmonization; 2005. [cited 2017 March 02]. Available from: http://www.ich.org/fileadmin/ Public_Web_Site/ICH_Products/Guidelines/Quality/Q2_R1/ Step4/Q2_R1_Guideline.pdf.

Itani KMF, Weigelt J, Li JZ, Duttagupta S. Linezolid reduces length of stay and duration of intravenous treatment compared with vancomycin for complicated skin and soft tissue infections due to suspected or proven methicillin-resistant Staphylococcus aureus (MRSA). Int J Antimicrob Agents. 2005;26(6):442-48.

Kalil AC, Puumala S, Stoner J. Is linezolid superior to vancomycin for complicated skin and soft tissue infections due to methicillin-resistant staphylococcus aureus? Antimicrob Agents Chemother. 2006;50(5):1910-11.

Kawy MA, Weshahy A, Shokry DS. Validated stability indicating assay of linezolid by spectrophotometric and high performance liquid chromatographic methods. Australian J Basic Appl Sci. 2012;6(3):767-78.

Kitahashi T, Furuta I. Method development for determining the antibacterial linezolid in human serum by micellar electrokinetic capillary chromatography. J Pharm Biom Anal. 2002;30(4):1411-16.

Kitahashi T, Furuta I. Further method development for measurement of linezolid in human serum by MEKC. J Pharm Biom Anal. 2004;35(3):615-20.

Krishna Reddy KV, Mahender Rao S, Om Reddy G, Suresh T, Moses Babu J, Dubey PK et al. Isolation and characterization of process-related impurities in linezolid. J Pharm Biom Anal. 2002;30(3):635-42.

La Marca G, Villanelli F, Malvagia S, Ombrone D, Funghini S, De Gaudio M. et al. Rapid and sensitive LC-MS/MS method for the analysis of antibiotic linezolid on dried blood spot. J Pharm Biom Anal. 2012;67-68:86-91.

Landers JP. Handbook of capillary electrophoresis. New York: CRC Press; 1997.
Lopes CCGO, Salgado HRN. Development of a validated stability-indicating LC assay and stress degradation studies of linezolid in tablets. Chromatogr. 2009;69(Suppl.2):S129-S135.

Lopes CCGO, Salgado HRN. Development and validation of a stability-indicative agar diffusion assay to determine the potency of linezolid in tablets in the presence of photodegradation products. Talanta 2010;82(3):918-22.

Marchese A, Schito GC. The oxazolidinones as a new family of antimicrobial agent. Clin Microbiol Infect. 2001;7(4): 66-74.

Merli D, Fasani E, Albini A, Profumo A. Analytical determination and electrochemical characterization of the oxazolidinone antibiotic linezolid. Electroanalysis. 2011;23(10):2364-72.

Michalska K, Pajchel G, Tyski S. Determination of enantiomeric impurity of linezolid by capillary electrophoresis using heptakis(2,3-diacetyl-6-sulfato)-beta-cyclodextrin. J Chromatogr A. 2008a;1180(1-2):179-86.

Michalska K, Pajchel G, Tyski S. Determination of linezolid and its achiral impurities using sweeping preconcentration by micellar capillary electrophoresis. J Pharm Biom Anal. 2008b;48(2):321-30.

Patel SA, Patel PU, Patel NJ, Patel MM, Bangoriya U. Determination of linezolid in pharmaceutical dosage forms by liquid chromatography and ultraviolet spectroscopy. J AOAC Int. 2007;90(5):1272-77.

Patel R, Gallagher JC. Vancomycin-resistant enterococcal bacteremia pharmacotherapy. Ann Pharmacother. 2015;49(1):6985.

Silva PSL, Monteiro Neto HM, Sejas LM. Successful treatment of vancomycin-resistant enterococcus ventriculitis in a child. Braz J Infect Dis. 2007;11(2):297-99.

Received for publication on $26^{\text {th }}$ September 2017 Accepted for publication on $28^{\text {th }}$ March 2018 